\title{
Análise das Ferramentas de Gestão Estratégica de Hotelaria Familiar: estudo de quatro organizações da região turística da Serra Gaúcha
}

\author{
Analysis of Strategic Management Tool for Family Hotels: study of four organizations in \\ the Brazilian Southern tourist Highland Region
}

Análisis de las Herramientas de Gestión Estratégica de los Hoteles Familiares: estudio de cuatro organizaciones de la región turística de la Sierra Gaucha de Brasil

Edegar Luis Tomazzoni ${ }^{1}$

Rafael de Bittencourt ${ }^{2}$

\begin{abstract}
Resumo
Apesar de ser comum, a gestão das empresas com base em desempenho e em resultados não é tarefa simples e fácil. No campo da estratégia empresarial, ferramentas adequadas de gestão são fundamentais para o desempenho organizacional. $\mathrm{O}$ objetivo do estudo foi analisar as ferramentas estratégicas de gestão de empresas hoteleiras familiares da região turística da Serra Gaúcha. Abordagens de administração estratégica e de gestão em hotelaria constituem a fundamentação teórica do artigo. A pesquisa é qualitativa e exploratória. Como objetos de estudo de caso, foram escolhidos: um Hotel em Caxias do Sul, uma Pousada em Gramado, uma Pousada em São Francisco de Paula, e uma Pousada em Bento Gonçalves. O Hotel é classificado como executivo, e as Pousadas de categoria luxo. A análise foi por meio de observação direta não participante dos meios de hospedagem e de entrevistas com aplicação de instrumento com 18 questões abertas aos seus gestores. Concluiu-se que a maior aplicação de ferramentas de gestão estratégica pelos gestores proporcionaria mais otimização dos resultados e mais vantagens competitivas às empresas hoteleiras familiares analisadas.
\end{abstract}

Palavras-chave: ferramentas de gestão; estratégias; hotelaria familiar; turismo; Serra Gaúcha (Brasil).

\begin{abstract}
Although common, the management of companies based on performance and results is not simple and easy task. In the field of corporate strategy, appropriate management tools are critical to organizational performance. The aim of this study was to analyze the strategic tools of family management hotel companies in the Brazilian Southtern Highland Region. Approaches to strategic management and management in hospitality form the theoretical

\footnotetext{
${ }^{1}$ Doutor em Ciências da Comunicação na Linha de Pesquisa em Turismo pela Escola de Comunicações e Artes da Universidade de São Paulo (USP). Docente da Escola de Artes, Ciências e Humanidades (EACH) da Universidade de São Paulo (USP). Brasil. E-mail: eltomazzoni@usp.br.

${ }^{2}$ Mestre em Turismo pela Universidade de Caxias do Sul (UCS); Professor da FTEC de Caxias do Sul (RS). Brasil. E-mail: rafaeldebittencourt@gmail.com.
} 
basis for the article. The research is qualitative and exploratory. As a case study objects were chosen: a Hotel in Caxias do Sul, a Hotel in Gramado, a hostel in San Francisco de Paula, and a hostel in Bento Gonçalves. The Hotel is classified as executive, and the hostels as luxury. The analysis was by means of direct observation, non-participation and interviews with the application of instrument with 18 open questions to the managers. It was concluded that a largest application of strategic management tools by managers would optimize results and provide more competitive advantages to the family hotel companies analyzed.

Keywords: management tools; family hotels; tourism; Southtern Highland Region (Brazil).

\section{Resumen}

Si bien es común, la evaluación de los resultados y del desempeño en los negocios, no es tan simples y fácil. En el campo de la estrategia corporativa, la medición del desempeño proporciona información básica para el control de la organización. El objetivo de este estudio fue investigar el uso de indicadores de desempeño para empresas hoteleras familiares de la región turística de la Sierra Gaucha (Brasil). La revisión teórica abarca la gestión estratégica, los diferentes modelos de evaluación del desempeño y la gestión de hoteles. Se trata de un estudio cualitativo, exploratorio, de casos específicos. Fueron elegidos como objetos de estudio un hotel en Caxias do Sul, una Posada en Gramado, una Posada en San Francisco de Paula, y una Posada en Bento Gonçalves. El hotel está clasificado como ejecutivo, y las posadas de categoría de lujo. Se concluyó que una mayor aplicación de herramientas de gestión estratégica optimizaría los resultados y lograr una mayor ventaja competitiva a los hoteles analizados.

Palabras clave: herramientas de gestión; hoteleria familiar; turismo; Sierra Gaucha (Brasil).

\section{Introdução}

Com instrumentos e técnicas analíticas, de conhecimento do microambiente e do macroambiente, os gestores posicionam a empresa para a vantagem competitiva, por meio da administração estratégica, focando a criação de valor para os clientes. Apesar de suas particularidades, as empresas hoteleiras familiares não são diferentes das demais organizações no que tange aos seus propósitos de oferecer conforto, comodidade e satisfação para os seus hóspedes.

Em razão das particularidades e das características próprias das empresas hoteleiras familiares, são necessárias ferramentas adequadas de gestão estratégica. Os gestores dos empreendimentos hoteleiros familiares precisam conhecer seu desempenho e o desempenho de suas equipes para serem mais competitivos no ambiente dos negócios. 
O objetivo geral deste estudo foi analisar a utilização de ferramentas para formular, implantar e monitorar estratégias de gestão organizacional pelos gestores de empresas hoteleiras familiares da Serra Gaúcha.

Para cumprir o objetivo geral, os objetivos específicos foram: 1) verificar se os gestores definem as diretrizes organizacionais e monitoram as variáveis microambientais e macroambientais; e 2) identificar as principais dificuldades e as visões dos gestores sobre a importância de ferramentas de mensuração e de avaliação de desempenho.

O método abrangeu a análise de dados qualitativos, coletados por meio de instrumento com questões abertas, aplicado aos proprietários e gestores das empresas hoteleiras, além de observação direta não participante. A aplicação do instrumento aos proprietários foi por meio de visitas realizadas entre os meses de março e maio de 2011. O instrumento de pesquisa constituiu-se de 18 questões, contemplando desde definição do negócio, missão, visão, até a utilização de ferramentas de gestão.

Os empreendimentos analisados foram: um Hotel em Caxias do Sul, uma Pousada em Gramado, uma Posada em São Francisco de Paula e uma Pousada em Bento Gonçalves. Os quatro municípios fazem parte da região da Serra Gaúcha, um dos principais destinos turísticos do país, de acordo com o Ministério do Turismo do Brasil (2012).

A escolha do hotel foi em razão de ser a maior empresa familiar em número de unidades habitacionais do segmento hoteleiro da cidade de Caxias do Sul. A escolha das Pousadas foi em razão de atenderem clientes de alto padrão aquisitivo, em razão de praticarem tarifas superiores a quatrocentos e cinquenta reais pela diária para casal, acima, portanto da média do segmento, que é, de acordo com a ABIH (2011), de pousadas de luxo. As pousadas destacamse, portanto, no segmento, em razão de seus preços, de seus padrões e do perfil de seus clientes de alto poder aquisitivo, o que as situa acima da média dos estabelecimentos do setor em seus respectivos municípios.

A profundidade e a originalidade deste artigo justificam-se por várias razões. O estudo contribui para o conhecimento de gestão estratégica de empresas de hotelaria, especialmente, as categoria familiar, segmento importante do turismo. Apesar de a administração estratégica ser campo tradicional, de autores clássicos e reconhecidos na área acadêmica, pouco se conhece sobre ferramentas de gestão estratégica das organizações hoteleiras familiares. 
Esta justificativa fundamenta-se no fato de que entre os 551 de artigos publicados, no período de abril de 2008 a abril de 2012, por seis dos principais periódicos científicos brasileiros da área de turismo, identificaram-se 54 estudos sobre hotelaria. Desses 54, apenas $20 \%$ (cerca de dez artigos) apresentam estudos específicos sobre gestão de hotelaria familiar ou da pequena empresa hoteleira. Na Revista Turismo em Análise, do total de 130 artigos publicados no período de abril de 2008 a abril de 2012, onze tratam de temas relacionados à hotelaria. Desses onze, quatro abordam temas relacionados à estratégia em hotelaria, e quatro abordam temas relacionados à hotelaria familiar ou à hotelaria de pequeno porte.

O referencial teórico estrutura-se em cinco seções: 1) administração estratégica, diretrizes organizacionais e análise ambiental; 2) ferramentas para formular estratégias; 3) ferramentas para implantar e para monitorar estratégias; 4) serviços, turismo e gestão em hotelaria; e 5) estudos sobre estratégias de gestão em hotelaria. Além da introdução, complementam a estrutura do artigo o método de pesquisa de campo e as considerações finais.

\section{Administração Estratégica, Diretrizes Organizacionais e Análise Ambiental}

A estratégia aplicada à gestão apresenta várias categorias de ferramentas. Uma delas é o planejamento estratégico, pelo qual se define a missão e a visão organizacional, assim como seus princípios, valores e negócio da empresa.

Com base em preceitos estratégicos, apresentam-se ferramentas para análise macroambiental e microambiental, e abordam-se modelos que auxiliam na formulação de estratégias de avaliação e de mensuração de desempenho, com base em conceitos de turismo e de hotelaria, em cenários e características do setor e de suas organizações.

A estratégia e a administração estratégica devem ser inerentes ao cotidiano dos executivos e das organizações. De acordo com Ansoff e McDonnel (2009), na evolução histórica, os sistemas de administração acompanharam as novas demandas. Inicialmente, a gestão era por controle, pois as mudanças eram lentas. Depois, a gestão era por extrapolação, pois, apesar de as mudanças serem um pouco mais rápidas, as previsões futuras eram baseadas nos históricos passados. 
A gestão por previsão começou a ser empregada quando começaram a surgir descontinuidades, apesar de as previsões e respostas serem oportunas. Por fim, surgiu a gestão por meio de respostas rápidas, em condições em que muitos desafios importantes surgiram exigindo previsões assertivas. Ansoff e McDonnel (2009) dizem também que, durante o século vinte, as crescentes turbulências têm levado as empresas a buscar sistemas administrativos mais complexos e refinados. Eles destacam duas tipologias de sistema: de posicionamento, em que se utiliza o planejamento estratégico, que orienta as ações das empresas em relação ao ambiente; e em tempo real, que reage às modificações ambientais rápidas e imprevistas.

As organizações como sistemas abertos precisam estar atentas, tanto ao ambiente externo quanto ao ambiente interno. Monitorar as influências e comportamentos desses ambientes é fundamental para suprir de informações os gestores que as planejam e as conduzem. Mintzberg, Aslstrand e Lampel (2000), Certo et al. (2005), Fernandes e Berton (2005), Hitt et al. (2008) são autores que fundamentam a abordagem do Ambiente Geral.

As variáveis do Ambiente Geral são: econômicas, que influenciam a demanda e o valor dos produtos e serviços; tecnológicas, que se referem ao desenvolvimento de produtos e serviços e ao avanço das ciências; sociais, que abrangem as configurações culturais, demográficas, ecológicas e as crenças e valores das pessoas e político legais, cujo contexto pode ser desde a globalização, até o âmbito local dos incentivos fiscais.

A análise do ambiente operacional retrata os elementos mais próximos para a organização, que, apesar de fazerem parte do ambiente externo, são relativamente controlados por ela. Os fatores do ambiente operacional são constituídos por: clientes; fornecedores; concorrentes; produtos e serviços substitutos, entre outros.

\section{Ferramentas para Formular Estratégias}

$\mathrm{Na}$ abordagem do Ambiente Operacional, destacam-se as cinco forças de Porter (2004): 1) ameaça de entrantes potenciais, que pode provocar queda de preços, inflação de custos dos participantes e redução de rentabilidade; 2) intensidade da rivalidade entre os concorrentes, 
cujas táticas envolvem preços, publicidade, serviços e garantias aos clientes; 3) pressão por produtos substitutos, que implica limitação de preços e redução de retornos; 4) poder de negociação dos compradores, que pressionam pela redução de preços e barganham qualidade, jogando concorrentes uns contra os outros; e 5) poder de negociação dos fornecedores, que podem elevar os preços ou reduzir a qualidade dos bens e serviços fornecidos.

Além do modelo de análise estrutural da indústria de Porter (2004), tem-se o modelo de Fernandes e Berton (2005), de análise do ciclo de vida do setor. Os autores dizem que toda indústria obedece a um ciclo de quatro etapas: introdução, crescimento, maturidade e declínio. A curva de maturidade pode ser prolongada ou encurtada, segundo a emergência de tecnologias concorrentes. Ainda, a posição do setor na curva determina a estratégia a seguir.

Os fatores internos da organização, desde sua estrutura de trabalho até os aspectos financeiros são abordagem fundamental da gestão estratégica. Certo et al (2005) conceituam o ambiente interno como o nível de ambiente da organização que está dentro dela e que normalmente tem implicação imediata e específica em sua administração. Diferentemente dos componentes dos ambientes geral e operacional, que existem fora da organização, os componentes do ambiente interno são os que estão facilmente perceptíveis e controláveis.

Para Fernandes e Berton (2005), de forma geral, o diagnóstico do ambiente interno da organização ou análise da organização, segue as seguintes etapas: identificação das competências da organização; análise da cadeia de valor; análise das estratégicas genéricas; e análise das áreas funcionais da empresa.

Wright et al (2009) estão entre os autores que destacam a Matriz BCG, criada pelo Boston Consulting Group (1967), como referência para a classificação dos negócios em "Questionamento", "Estrelas", "Vacas Leiteiras" e "Abacaxis". Os autores destacam também a Matriz SWOT (strenghts, weakness, oppotunities, threats), para a identificação de oportunidades e de ameaças, de pontos fortes e de pontos fracos.

Para Vasconcelos Filho e Pagnoncelli (2001), na avaliação dos resultados e correção dos rumos da organização, o processo de planejamento estratégico deve seguir as seguintes etapas: a) definição do negócio; b) missão; c) análise do ambiente; d) visão; e) objetivos; f) estratégias competitivas; g) ações proativas; e h) processo de controle e desempenho estratégico. 
Para Kluyver e Pearce II (2007), quando mudar uma cultura corporativa for fundamental para melhorar o desempenho ou implantar uma nova orientação estratégica, a gestão dos resultados pode não ser suficiente. Em vez disso, pode ser necessário um estilo de gestão de controle de comportamento. A empresa monitora diretamente o comportamento de equipes de unidades específicas de negócios, de equipes executivas ou de gerentes específicos.

Assen et al (2010) destacam o modelo de análise DuPont, que pode ser aplicado de muitas maneiras, como por exemplo, para o benchmarking, isto é, comparação entre diferentes empresas de um setor para descobrir porque algumas delas atingem retornos superiores de empresas semelhantes. Wright et al (2009) salientam que o controle estratégico pode ser visualizado como um medidor das interações entre as variáveis ambientais e as operações internas da organização. Oliveira (2009) explica que as finalidades do controle são identificar problemas, melhorar resultados, verificar as estratégias e produzir informações.

As ferramentas de gestão contemplam a avaliação do desempenho organizacional. Para Dutra e Ensslin (2008), a eficácia de um método de avaliação de desempenho pode ser caracterizada pelo atendimento, em maior ou menor intensidade, dos graus de: personalização, ambiguidade, priorização, flexibilidade, geração de conhecimento, e geração de aperfeiçoamento.

\section{Ferramentas para Implantar e para Monitorar Estratégias}

Kaplan e Norton (2004b) salientam a necessidade de utilizar ferramentas de gestão de desempenho, além das contábeis e financeiras tradicionais, pois, às vezes, fornecem informações enganosas para fins de melhoria contínua e de inovação. Norton e Kaplan (1997) destacam o balanced scorecard (BCS), cujas perspectivas são: financeira, clientes, processos internos, aprendizado e crescimento.

Para Kaplan e Norton (2004b), as declarações de missão devem ser inspiradoras, devem fornecer energia e motivação à empresa. Mas declarações de missão e slogans inspiradores não são suficientes. O balanced scorecard (BSC) é uma ferramenta abrangente, que traduz a visão e a estratégia da empresa num conjunto coerente de medidas de desempenho. Herrero (2005) reconhece que o BCS é um paradigma da gestão empresarial, incorporando, pela visão 
holística, as principais ideias sobre gestão de negócios, defendidas por seus principais intelectuais.

A ferramenta Servqual ou Qualserv (Qualidade em Serviço) foi criada por Parasuraman, Zeithaml e Berry (1985) para analisar as dimensões: acessibilidade, competência, comunicação, conhecimento do cliente, confiabilidade, cortesia, credibilidade, empatia, responsividade, segurança e tangibilidade. Para os autores, qualidade é a relação entre a expectativa do consumidor e a qualidade do serviço prestado pela empresa. Essa ferramenta fundamenta-se na satisfação das necessidades dos clientes.

Assen et al. (2010) destacam os sete elementos essenciais (7S) da gestão organizacional: estratégia (strategy), estrutura (structure), sistemas (systems), habilidades (skills), equipe (staff), estilo (style) e valores compartilhados (shared values). A premissa é que esses sete elementos devem estar alinhados, pois se reforçam mutuamente, constituindo-se em ferramenta de gestão competente. Esses elementos organizacionais interdependentes podem ser classificados como inflexíveis ou flexíveis. Os inflexíveis ou tangíveis são estratégias, estrutura e sistemas. Os flexíveis ou emocionais - estilo e habilidades - são compartilhados pela equipe.

Rappaport (1986) apresenta a Gestão Baseada em Valor como ferramenta para maximizar o valor de uma empresa, que usa técnicas de avaliação para gestão de desempenho, controle de negócios e processo decisório. O valor de uma empresa é determinado com base nos descontos de seus fluxos de caixa, quando ela investe capital de modo a obter retornos que superem o custo do investimento. Todas as estratégias e decisões são testadas em relação ao potencial de criação de valor.

Outra ferramenta importante é o yield management, ou gerenciamento de receitas. Para Sfodera (2011), yield management é um conceito empregado em empresas aéreas e em redes hoteleiras no mercado internacional desde a década de 1980. O Gerenciamento de Receitas é uma abordagem sistemática para as decisões de preços por meio do gerenciamento de disponibilidades dos serviços (quartos de hotel, por exemplo) e gerenciamento de preços. $\mathrm{O}$ objetivo primário é a maximização do lucro em qualquer período. Os preços são ajustados para refletirem a demanda prevista. A chave do sucesso para implantação da técnica é a análise de previsão de demanda. 


\section{Serviços, Turismo e Gestão em Hotelaria}

Para Lovelock e Wright (2001), serviços são atividades econômicas que criam valor e fornecem benefícios para clientes em tempos e lugares específicos, como decorrência da realização de uma mudança desejada no ou em nome do destinatário do serviço. Os autores salientam que com a crescente consciência de que a melhoria da qualidade era boa para o negócio e necessária para a competição eficaz, ocorreu uma mudança radical no pensamento. Noções tradicionais de qualidade foram substituídas pelo novo imperativo de deixar a qualidade ser dirigida pelo cliente, o que trouxe enormes consequências para a importância do marketing de serviços e o papel da pesquisa junto aos clientes.

A gestão de serviços em hotelaria contextualiza-se no turismo como sistema constituído por produtores, distribuidores e consumidores e seus respectivos subsistemas, sendo um deles o alojamento. (FOSTER, 1999; SCHUCH, 2001; TOMAZZONI, 2009). Para que o turista possa desfrutar da oferta de atrativos, muitas empresas são envolvidas, e várias delas são do setor de serviços, como os hoteis familiares. Entender a sistemática da gestão, a aplicabilidade de ferramentas de gestão, assim como, a análise ambiental, são elementos que influenciam no sucesso do empreendimento hoteleiro. Esses elementos devem ser identificados e estudados em profundidade desde a constituição do estabelecimento hoteleiro.

Para Castelli (2003), a constituição do estabelecimento hoteleiro responde a uma série de fatores. Entre eles, podem-se destacar a finalidade e o propósito do estabelecimento hoteleiro, sendo o de criar um serviço de hospedagem tipicamente turístico, para satisfazer a necessidade específica do indivíduo, como decorrência do fluxo turístico e do crescimento da atividade comercial e de intercâmbio.

Para Walker (2002), nos hotéis de pequeno e médio portes, a estrutura de gerenciamento será bem menos complexa do que nos estabelecimentos de maior porte. Alguém, entretanto, irá se responsabilizar pelas áreas fundamentais, sem as quais a administração não lograria êxito. $\mathrm{O}$ gerente-geral assumirá a responsabilidade final por todas as decisões concernentes a seu departamento. A mesma situação pode acontecer nas áreas de: engenharia e manutenção, contabilidade e finanças, vendas e marketing, gerenciamento de alimentos e bebidas, etc. 
É importante abordar também as características das empresas familiares, um dos focos deste estudo. Para Oliveira (1999), a empresa familiar caracteriza-se pela sucessão do poder decisório de maneira hereditária, de uma ou mais famílias. Outra característica é que as empresas familiares geralmente apresentam melhores resultados que outras empresas em relação às questões de qualidade, pois o nome da família é associado aos produtos e serviços que são oferecidos ao mercado.

Para Lodi (1998), na empresa familiar, profissionalização implica ter sucesso em: integrar profissionais familiares na direção e na gerência da empresa; adotar práticas administrativas mais racionais; recorrer a consultorias e a assessorias externas para incorporar sistemas de trabalho já exitosos em empresas mais avançadas ou recomendados nas universidades e nos centros de pesquisa.

A concorrência, principalmente com empresas hoteleiras internacionais, estimula a mudança nas empresas hoteleiras familiares. Ribeiro (2005) comenta que, no passado, as decisões nos hoteis de gestão familiar, eram influenciadas por critérios emocionais e afetivos. Hoje já nem tanto, mas em alguns estabelecimentos esse aspecto ainda está presente.

Em razão do aumento da competitividade, as empresas hoteleiras buscam a excelência na prestação do serviço, que se obtém por meio de educação e de capacitação profissional. Produtividade, qualidade, redução dos custos são fatores de competitividade e de estabilidade organizacional em hotelaria. Para implantação de serviços de hotelaria, Castelli (2003) ensina que as estratégias são: segmentar o mercado, descobrir as expectativas dos clientes e ajustar os serviços às expectativas.

O mesmo autor identifica alguns entraves nas empresas hoteleiras: inércia às mudanças, em razão da situação confortável no qual os hotéis estavam nas décadas de 1970 e 1980; a classificação hoteleira atribuiu $70 \%$ dos pontos às instalações e somente $30 \%$ aos serviços; e falta de investimento. Ele destaca a importância da coleta, por meio de pesquisas, da opinião dos clientes, tanto internos quanto externos, sobre a sua satisfação no que diz respeito à qualidade dos serviços recebidos. Afinal, são eles que a definem e a julgam. Daí a necessidade de criarem-se instrumentos que permitam captar esse julgamento de forma permanente e sistemática. 
Um dos indicadores de produtividade é o Revpar, que significa, em inglês, revenue per available room, isto é, receita por quarto disponível. É uma medida de balanço entre a oferta de quartos de hotel com a demanda (hóspede) e pode ser calculada de duas formas: multiplicando-se a tarifa média de um hotel pela taxa de sua ocupação; ou dividindo-se o total de receitas do hotel pelo número de quartos por noite disponíveis no período estudado.

Apesar de ser o índice de produtividade mais utilizado no setor hoteleiro, segundo Lohmann e Panosso Netto (2008), existem várias críticas a seu respeito. Questiona-se o Revpar como não sendo um bom indicador de produtividade, uma vez que leva em conta apenas as receitas geradas nas contas dos quartos, excluindo, por exemplo, gastos dos hóspedes nos restaurantes e nas lojas do hotel. Slattery apud Lohmann e Panosso Netto (2008) fez críticas também à falta de padronização das variáveis que compõem o Revpar, sugerindo algumas alternativas para práticas adotadas muitas vezes pelas empresas hoteleiras, apenas como intuito de aumentar o índice de produtividade.

\section{Estudos sobre Estratégias de Gestão em Hotelaria}

Nesta seção, apresentam-se sínteses de alguns estudos publicados em periódicos brasileiros de turismo. Os critérios de seleção dos artigos foram abordagens de estratégias em hotelaria, gestão de hotelaria familiar e de pequena empresa hoteleira.

Pereira e Lucena (2009) realizaram estudo sobre as estratégias da Accor Hotels do Brasil entre 1974 e 2006 e constataram que o processo de formação das estratégias corporativas ocorreu predominantemente pelo modo de planejamento. Esse modo é um das tipologias identificadas por Mintzberg (1973), do papel do gestor como analista do processo, que pode utilizar técnicas da ciência administrativa e da política de análise para delinear as estratégias. Pereira e Lucena (2009) notaram também que todo o processo da rede pesquisada enquadra-se na abordagem do incrementalismo lógico, de Quinn (1978), em que o processo de formação das estratégias desenvolve-se em fases, e cada uma sustenta-se nas anteriores. A organização pode seguir passo a passo, utilizando-se também de mudanças estratégicas de acordo com as forças dos ambientes interno e externo. 
Gohr e Santos (2010) identificaram que as estratégias adotadas por onze empresas do setor hoteleiro (seis empresas familiares) de um município catarinense com elevado fluxo de turistas estão relacionadas com a própria estrutura competitiva, que faz com que as empresas adotem um conjunto diversificado de estratégias. Para Gohr e Santos (2010, p.316),

As empresas adotavam uma série de comportamentos e posicionamentos estratégicos. As razões para a adoção de diferentes tipologias estratégicas são muitas, mas principalmente, porque as empresas estavam buscando manter-se a qualquer custo no mercado, seja para a busca de uma melhor rentabilidade financeira, seja para a sua própria sobrevivência. As empresas que compunham o setor adotavam diferentes estratégias, sendo a liderança de custo e o comportamento prospectivo as mais frequentes.

Martins, Lobo e Carrieri (2010) identificaram necessidades e expectativas de pousadas nas cidades históricas de Ouro Preto e Tiradentes na Estrada Real (MG), em termos de estratégia para a logística de suprimentos. Os autores (2010, p. 320) argumentam que "no caso dos serviços relacionados ao turismo, o uso estratégico da logística permite alcançar diferenciais competitivos tanto no aspecto custos quanto na qualidade do atendimento". Martins, Lobo e Carrieri (2010, p. 337) constataram que "os suprimentos devem ser realizados com responsividade, em ate 24 horas, por um ou poucos fornecedores, em lotes pequenos, que são entregues nos estabelecimentos pelos fornecedores. A troca compensatória que os gestores estariam dispostos a fazer seria a de abrir mão de poucos fornecedores, mas mantendo os demais atributos".

Com base na visão de que as organizações do turismo precisam considerar relacionamentos com organizações de outros setores, além do próprio turismo, Brunelli e Macedo-Soares (2012) analisaram o caso de redes de hotéis líderes da cidade do Rio de Janeiro (Windsor, Othon e BHG). As oportunidades e as ameaças das alianças hoteleiras estratégicas foram consideradas tanto para competir no cenário global quanto para o desenvolvimento do destino turístico. Os aspectos macroambientais, os atores estratégicos chaves e os elementos das alianças e das redes constituíram os fatores não-relacionais e relacionais da análise. Os resultados mostraram que novos insights gerenciais são revelados, pois com os fatores relacionais na análise estratégica, a maioria das ameaças é neutralizada. Além disso, o 
potencial das alianças proporciona oportunidades para o desenvolvimento turístico da cidade pelos hotéis.

Com objetivo de analisar o processo sucessório em uma empresa familiar no ramo de turismo, Jesus, Machado e Jesus (2009) escolheram o caso de sucessão da primeira para a segunda geração e em fase de transição para a terceira geração. Os autores (2009) constataram que não houve preparo prévio para a sucessão, como recomenda a literatura, mas que a transição foi favorecida principalmente por três aspectos: a perspectiva favorável do setor, a liderança assumida por uma das sucessoras e a imagem do sucedido.

A relação entre o ambiente organizacional e o comportamento estratégico no setor hoteleiro de Florianópolis (SC) foi o estudo de Teixeira, Rossetto e Carvalho (2009). A conclusão foi que, na percepção de incerteza ambiental, os administradores que adotam estratégias prospectoras (novos mercados, produtos e serviços) tendem a ser os mesmos que percebem mais variáveis como geradoras de incertezas ambientais.

Pedrosa e Sousa (2009) estudaram a atitude empreendedora em pequenos e grandes hotéis no Distrito Federal e concluíram que gerentes dos pequenos hotéis planejam, inovam e fazem mais esforços que gerentes dos grandes hotéis que, em contrapartida, aceitam mais desafios que aqueles. Gimenez e Gimenez (2010) analisaram a relação entre atitude empreendedora e estratégias de atuação no mercado por pequenos e médios hotéis de Curitiba (PR) e constataram que, para hoteleiros de alta orientação empreendedora, as estratégias prospectoras foram mais atraentes, e que os dirigentes de pequenos e médios hotéis têm atitude empreendedora menos audaciosa, pois adotaram estratégias defensivas.

Estes estudos são exemplos de contribuições importantes da academia para o campo da gestão estratégica de empresas hoteleiras, segmento fundamental do turismo. A produção de conhecimento científico em hotelaria ainda é recente no Brasil, o que representa múltiplas possibilidades e oportunidades de produção, a fim de suprir as necessidades de inovações e de competividade mercadológica do segmento, conforme mostram as publicações destacadas nesta seção.

\section{Método de Pesquisa}


Com base na revisão teórica, apresenta-se o mapa conceitual do Quadro 1, que embasou a pesquisa de campo, realizada por meio de entrevistas com aplicação de instrumento com questões abertas aos gestores e de visitas para observação direta não participante dos meios de hospedagem analisados.

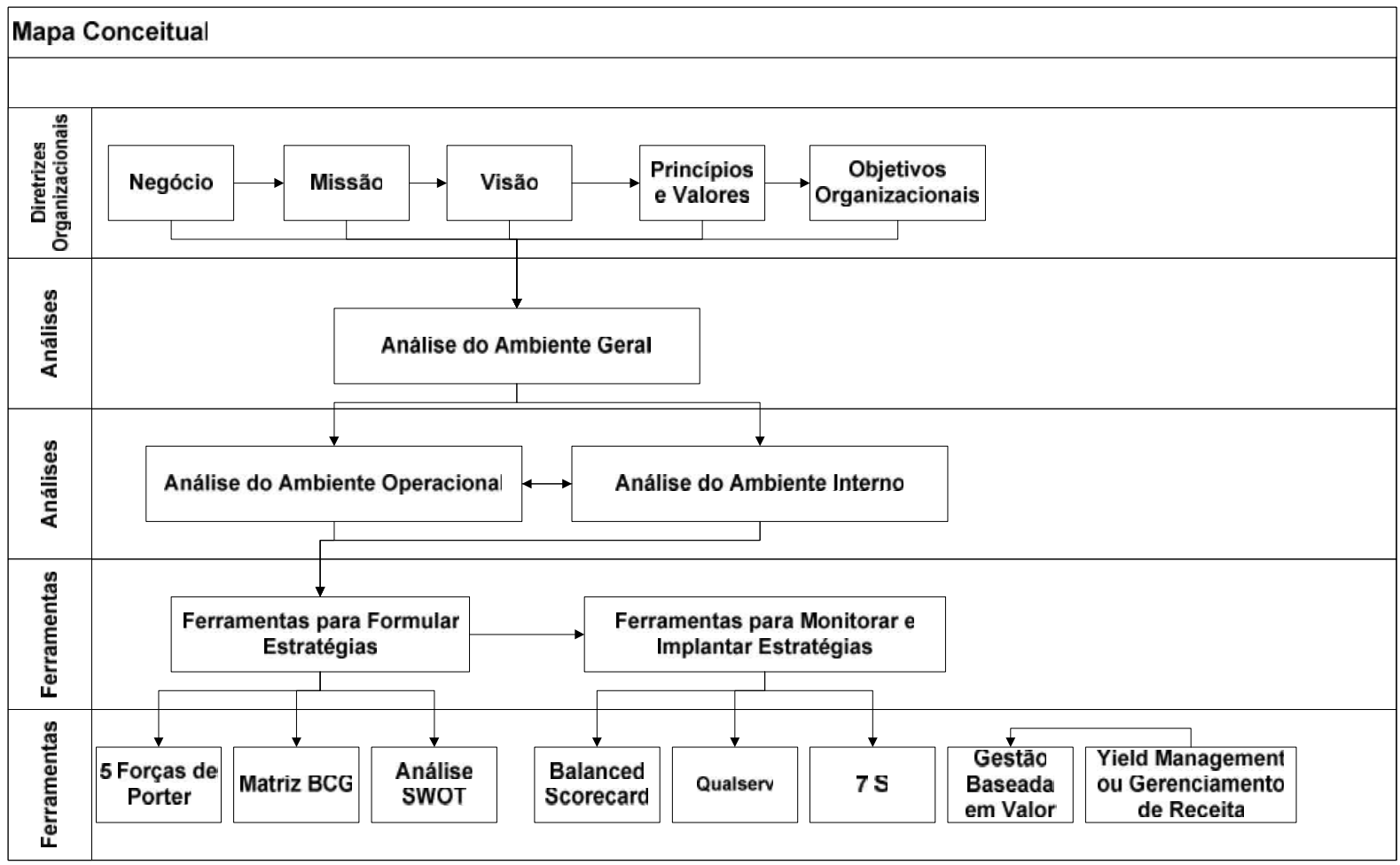

De acordo com o mapa conceitual, as diretrizes organizacionais destacadas são: definição do negócio; missão; visão; princípios e valores e objetivos organizacionais. A análise ambiental abrange: ambiente geral, ambiente operacional e ambiente interno. As ferramentas para formular estratégias são: cinco forças de Porter; matriz BGC, análise SWOT. As ferramentas para formular e para implantar estratégias são: balanced scorecard (BSC), qualiserv; 7 S; gestão baseada em valor e yield management ou gerenciamento de receita.

O percurso metodológico do mapa conceitual fundamentou as questões abertas do instrumento de pesquisa de campo. A aplicação do instrumento aos gestores das quatro empresas hoteleiras familiares, por meio de visitas e de entrevistas, foi entre os meses de março e maio de 2011. Os empreendimentos analisados foram: um Hotel em Caxias do Sul, 
uma Pousada em Gramado, uma Posada em São Francisco de Paula, e uma Pousada em Bento Gonçalves.

A análise de conteúdo foi o método qualitativo aplicado à interpretação das repostas das entrevistas. Trata-se de técnica para descrever e interpretar o conteúdo de toda classe de documentos e textos. A análise de conteúdo orienta-se por critérios como: contexto, objeto ou corpus da análise, sujeitos entrevistados, questões formuladas, objetivos da pesquisa, subjetividade e isenção científica do pesquisador. (BARDIN, 1977; BARROS e LEHFELD, 1991; MOARAES, 1994).

A escolha do Hotel foi em razão de ser maior empresa familiar em número de unidades habitacionais do segmento hoteleiro de Caxias do Sul. A escolha das Pousadas foi em razão de atenderem clientes de alto padrão aquisitivo, pois praticam tarifas superiores a quatrocentos e cinquenta reais pela diária para casal. Atuam em segmento complexo e exigente, que, conforme classificações da ABIH (2010) é de pousadas de luxo, no contexto da Serra Gaúcha, um dos principais destinos turísticos do país, de acordo com o Ministério do Turismo do Brasil (2012). Os dados sobre os empreendimentos (números de apartamentos, tarifas, números de colaboradores) foram obtidos pelas entrevistas com os gestores, durante a pesquisa de campo.

O Hotel pesquisado localiza-se na área central da cidade de Caxias do Sul, oferece 90 apartamentos divididos nas opções suíte de luxo, suíte executivo, apartamentos de luxo, apartamentos executivos e apartamentos standard. As tarifas por casal variam de 230 reais a 350 reais. O Hotel, cuja gestão é familiar, dispõe de 30 colaboradores, com uma gestão profissionalizada pelos sócios-diretores e coordenadores de área, como comercial, administrativo-financeiro, recepção e reservas, limpeza e arrumação, alimentação e bebidas. Os hóspedes são predominantemente executivos da região sul que se hospedam durante a semana. A taxa média de ocupação é de $49 \%$. As ações de divulgação e captação de hóspedes são por meio eletrônico e convênios com empresas locais.

Caxias do Sul tem população de 435.482 habitantes (IBGE, 2010). De acordo com a Câmara de Indústria, Comércio e Serviços de Caxias do Sul (CIC, 2011), os setores da economia dividem-se em indústria, com 50\% (6.665 empresas), comércio e serviços, com 38\% (21.923 empresas), e agropecuária com 4,5\% (444 empresas). O setor industrial é composto 
principalmente pelos segmentos metalmecânico, material de transporte, mobiliário, produtos alimentícios e bebidas. Na oferta turística, de acordo com o Sindicato de Hotéis, Restaurantes, Bares e Similares da Região Uva e Vinho (SHRBS, 2011), o município tem 21 hotéis e 10 pousadas.

A Pousada localizada em Gramado oferece 17 unidades habitacionais divididas em três categorias, cujas tarifas variam de 570 reais a 1.454 reais por casal. É administrado pela proprietária, que tem formação superior na área de ciências sociais, por uma gerente geral, que tem formação em hotelaria, e por uma agência de marketing. Oferece serviços de alto padrão para um público de alto poder aquisitivo, conforme se verifica pelos preços das diárias. Na Pousada, trabalham diretamente 25 colaboradores. Os hóspedes são, na sua maioria, provenientes da região sudeste do Brasil. O público-alvo são casais em busca de lazer em um local romântico. A taxa de ocupação é aproximadamente $60 \%$, e a demanda maior é nos finais de semana.

Gramado tem uma população de 33.706 habitantes. (IBGE, 2010). De acordo com a Prefeitura Municipal (2011), a economia do município tem no turismo a sua principal fonte de receita. Recebe anualmente cerca de três milhões de turistas. Móveis, chocolates, couro, malhas, ferramentas e a construção civil também contribuem para a geração de emprego e renda. Conforme o Sindicato da Hotelaria, Bares, Restaurantes e Similares da Região das Hortênsias (2011), Gramado dispõe de 69 hotéis e 67 pousadas.

A Pousada localizada no município de São Francisco de Paula dispõe de 12 cabanas com uma cama de casal cada uma e a possibilidade de uma cama de casal extra, com tarifas diárias para casal de 450 reais a 735 reais. A empresa é constituída por três sócios, um deles administrador principal da pousada, que mantém 16 colaboradores diretos. Os hóspedes são na sua grande maioria provenientes do Rio Grande do Sul, e a maior taxa de ocupação é nos finais de semana. A taxa média anual de ocupação é de $50 \%$.

São Francisco de Paula localiza-se a 112 quilômetros da capital Porto Alegre, na interseção geográfica entre as microrregiões das Hortênsias e Campos de Cima da Serra. Sua população é de 22.000 habitantes, e a principal atividade econômica é a agropecuária. Conforme o Sindicato da Hotelaria, Bares, Restaurantes e Similares da Região das Hortênsias (2011), o 
município tem sete hoteis, 21 pousadas, além de 13 meios de hospedagem em fazendas (campings e albergues).

A quarta organização é a Pousada no município de Bento Gonçalves, com 24 suítes, somando 53 leitos. Foi construída em vários níveis, em estilo rústico sofisticado, harmonizado com o meio ambiente da cultura local. Mantém 16 colaboradores diretos. O público-alvo é de turistas da região sul e sudeste, e a taxa de ocupação é de $57 \%$. O preço médio das diárias para casal é de 460 reais. Os proprietários mantêm negócios ligados a outros segmentos do município, especialmente à atividade vinícola.

Bento Gonçalves localiza-se a 124 quilômetros da capital Porto Alegre. Sua população é de 107.341 habitantes. (IBGE 2010). É o maior polo moveleiro do estado. Destacam-se na economia também os setores vinícolas, metalúrgico, de transportes e frutícola. O turismo vinícola (enoturismo) atrai a maioria dos mais de um milhão de turistas por ano. Conforme o Sindicato de Hotéis, Restaurantes, Bares e Similares da Região Uva e Vinho (2011), o município tem 11 hotéis e 15 pousadas.

\section{Análise das Ferramentas Utilizadas pelos Gestores das Organizações Pesquisadas}

No Hotel localizado em Caxias do Sul, os gestores utilizam ferramentas modernas com foco no mercado, por influência das ações propostas pela agência de marketing. O hotel utiliza ferramentas de gestão estratégica e de avaliação de desempenho, nas áreas financeiras, de marketing, de pessoas e de processos internos. Na área financeira, apresentam ferramentas adequadas, implantadas pela empresa de contabilidade que presta serviços ao hotel. A utilização de um software de gestão hoteleira também formaliza alguns processos e monitora as informações relacionadas às reservas e às demandas dos clientes. O Hotel apresenta dificuldades em formalizar seus processos e registros de gestão de pessoas e de capacitação, assim como aquelas voltadas a processos e melhorias contínuas. A gestão estratégica e a aplicação de suas ferramentas também deveriam ser formalizadas, em especial, a aplicação do planejamento estratégico. Para os gestores, as ferramentas de mensuração e de avaliação de desempenho são fundamentais para análise dos resultados obtidos e para definição de novas estratégias. 
Na Pousada localizada em Gramado, todos os funcionários têm consciência do negócio e do seu posicionamento quanto ao público que é atendido. Os gestores utilizam as informações microambientais por meio do perfil do cliente e dos canais de comunicação, principalmente internet, pelos quais obtêm as informações sobre: segmentos de clientes, concorrentes, produtos e serviços, tendências de mercado. As pesquisas de fornecedores, em razão da pouca oferta na região, tornam-se limitadas. A comunicação é realizada praticamente por meio virtual, como site da empresa e e-mail marketing. As ferramentas utilizadas pelos gestores da Pousada são cinco forças de Porter, matrizes BCG e SWOT, além de análise de tendências do mercado local. O ROI (Retorno sobre o Investimento) é o índice de produtividade mais utilizado. As principais dificuldades dos gestores, na mensuração e avaliação de desempenho organizacional, é realizar o yield management, ou gerenciamento de receitas, em uma empresa pequena, em que cada quarto é diferente dos demais, e muitos fatores impactam na projeção de demanda. Para os gestores, as ferramentas de mensuração e de avaliação de desempenho são muito importantes.

Os gestores e funcionários da Pousada localizada em São Francisco de Paula utilizam ferramentas para formular estratégias em reuniões periódicas. As ações comerciais de captação de hóspedes são por meio de site, revistas especializadas, folheteria e e-mail marketing. Os gestores não utilizam ferramentas para monitorar a implantação e aplicação das estratégias, e suas principais dificuldades são a falta de colaboradores qualificados e a formalização do processo de planejamento estratégico. As ferramentas de mensuração e de avaliação de desempenho organizacional consistem em informações financeiras e em instrumentos de avaliação da satisfação dos clientes. Suas principais dificuldades na mensuração e avaliação de desempenho organizacional são a falta de controles formais e de instrumentos de avaliação de desempenho. A Pousada utiliza as informações decorrentes da mensuração e avaliação de desempenho organizacional para orientar as discussões periódicas com os sócios e com a equipe a fim de auxiliar na tomada de decisão. Os gestores definem a utilização de ferramentas de avaliação de desempenho como necessária para a tomada de decisões.

Para os gestores da Pousada localizada em Bento Gonçalves, estratégias servem para tomar decisões rápidas diante das oportunidades e ameaças para desenvolver prognósticos eficazes. 
Gestão estratégica é otimizar as vantagens competitivas em relação ao ambiente onde atuam, conhecendo os pontos fortes e fracos, bem como seus concorrentes e a clareza de seus objetivos. A análise das variáveis macroambientais é feita eventualmente. Mesmo não se caracterizando uma prática permanente, aplicam as informações como indicadores, a fim de identificar elementos que possam influenciar a organização. A principal dificuldade das estratégias na Pousada é a implantação e adaptação do quadro funcional e mensuração de alguns dados. Adequar-se a novos processos exige uma mobilização integral das equipes. Os gestores e funcionários avaliam a satisfação dos hóspedes e seu perfil, a ocupação das unidades habitacionais e metas para os departamentos de reserva e recepção e fazem benchmarking, pois entendem que é fundamental adequar a Pousada a um plano estratégico eficaz para ter competitividade no mercado. As principais ações de comunicação e marketing são por meio digital e por divulgação em veículos de comunicação especializados. Para os gestores, as ferramentas de mensuração e de avaliação de desempenho são extremamente necessárias à visibilidade e sucesso do empreendimento.

\begin{tabular}{|c|c|c|c|c|}
\hline & $\begin{array}{l}\text { Hotel em Caxias do } \\
\text { Sul }\end{array}$ & $\begin{array}{l}\text { Pousada em } \\
\text { Gramado }\end{array}$ & $\begin{array}{l}\text { Pousada em São } \\
\text { Francisco de Paula }\end{array}$ & $\begin{array}{l}\text { Pousada em } \\
\text { Bento } \\
\text { Gonçalves } \\
\end{array}$ \\
\hline Negócio & $\begin{array}{l}\text { definido } \\
\text { formalmente }\end{array}$ & $\begin{array}{l}\text { definido } \\
\text { informalmente }\end{array}$ & $\begin{array}{l}\text { definido } \\
\text { informalmente }\end{array}$ & $\begin{array}{l}\text { definido } \\
\text { formalmente }\end{array}$ \\
\hline Missão & $\begin{array}{l}\text { definida } \\
\text { formalmente }\end{array}$ & $\begin{array}{l}\text { definida } \\
\text { informalmente }\end{array}$ & $\begin{array}{l}\text { definida } \\
\text { informalmente }\end{array}$ & $\begin{array}{l}\text { definida } \\
\text { formalmente }\end{array}$ \\
\hline Visão & $\begin{array}{l}\text { definida } \\
\text { formalmente }\end{array}$ & $\begin{array}{l}\text { definida } \\
\text { informalmente }\end{array}$ & $\begin{array}{l}\text { definida } \\
\text { informalmente }\end{array}$ & $\begin{array}{l}\text { definida } \\
\text { formalmente }\end{array}$ \\
\hline $\begin{array}{l}\text { Princípios e } \\
\text { Valores }\end{array}$ & $\begin{array}{l}\text { definidos } \\
\text { formalmente }\end{array}$ & $\begin{array}{l}\text { definidos } \\
\text { sinformalmente }\end{array}$ & $\begin{array}{l}\text { definidos } \\
\text { informalmente }\end{array}$ & $\begin{array}{l}\text { definidos } \\
\text { formalmente }\end{array}$ \\
\hline $\begin{array}{l}\text { Objetivos } \\
\text { Estratégicos }\end{array}$ & $\begin{array}{l}\text { definidos } \\
\text { formalmente }\end{array}$ & $\begin{array}{l}\text { definidos } \\
\text { informalmente }\end{array}$ & $\begin{array}{l}\text { definidos } \\
\text { informalmente }\end{array}$ & $\begin{array}{l}\text { definidos } \\
\text { formalmente }\end{array}$ \\
\hline $\begin{array}{l}\text { Estratégia e } \\
\text { Gestão Estratégica }\end{array}$ & $\begin{array}{l}\text { gestão interna da } \\
\text { organização }\end{array}$ & $\begin{array}{l}\text { ferramentas } \\
\text { práticas de auxilio } \\
\text { à gestão }\end{array}$ & atividade prática & visão clara \\
\hline Microambiente & $\begin{array}{l}\text { definido } \\
\text { formalmente }\end{array}$ & $\begin{array}{l}\text { definido } \\
\text { formalmente }\end{array}$ & $\begin{array}{l}\text { definido } \\
\text { informalmente }\end{array}$ & $\begin{array}{l}\text { definido } \\
\text { formalmente }\end{array}$ \\
\hline Macroambiente & $\begin{array}{l}\text { definido } \\
\text { formalmente }\end{array}$ & $\begin{array}{l}\text { definido } \\
\text { formalmente }\end{array}$ & $\begin{array}{l}\text { definido } \\
\text { informalmente }\end{array}$ & $\begin{array}{l}\text { definido } \\
\text { formalmente }\end{array}$ \\
\hline
\end{tabular}




\begin{tabular}{|c|c|c|c|c|}
\hline $\begin{array}{l}\text { Ferramentas para } \\
\text { formular } \\
\text { estratégias }\end{array}$ & conhecimento & $\begin{array}{l}\text { cinco forças de } \\
\text { Porter, matrizes } \\
\text { BCG e SWOT }\end{array}$ & reuniões periódicas & $\begin{array}{l}\text { pesquisas de } \\
\text { indicadores } \\
\text { econômicos, } \\
\text { socioculturais } \\
\text { e ambientais }\end{array}$ \\
\hline $\begin{array}{l}\text { Ferramentas para } \\
\text { monitorar } \\
\text { estratégias }\end{array}$ & utiliza & utiliza & não utiliza & utiliza \\
\hline $\begin{array}{l}\text { Ferramentas para } \\
\text { mensurar e avaliar } \\
\text { o desempenho } \\
\text { organizacional }\end{array}$ & $\begin{array}{l}\text { controle financeiro e } \\
\text { de satisfação de } \\
\text { clientes }\end{array}$ & $\begin{array}{l}\text { ROI e avaliação de } \\
\text { satisfação do } \\
\text { cliente }\end{array}$ & $\begin{array}{l}\text { informações } \\
\text { financeiras e } \\
\text { instrumentos de } \\
\text { avaliação da } \\
\text { satisfação dos } \\
\text { clientes }\end{array}$ & $\begin{array}{l}\text { inspeções nas } \\
\text { unidades } \\
\text { habitacionais, } \\
\text { instrumento } \\
\text { de avaliação } \\
\text { da satisfação } \\
\text { do cliente, } \\
\text { controle da } \\
\text { taxa de } \\
\text { ocupação, } \\
\text { metas de } \\
\text { reserva e } \\
\text { recepção }\end{array}$ \\
\hline $\begin{array}{l}\text { Utilização de } \\
\text { ferramentas de } \\
\text { mensuração e de } \\
\text { avaliação de } \\
\text { desempenho }\end{array}$ & utiliza & utiliza & utiliza & utiliza \\
\hline $\begin{array}{l}\text { Importância da } \\
\text { utilização de } \\
\text { ferramentas de } \\
\text { mensuração e de } \\
\text { avaliação de } \\
\text { desempenho }\end{array}$ & $\begin{array}{l}\text { fundamentais para } \\
\text { análise dos } \\
\text { resultados obtidos e } \\
\text { para definição de } \\
\text { novas estratégias }\end{array}$ & muito importante & $\begin{array}{l}\text { necessária para a } \\
\text { tomada de } \\
\text { decisões na gestão }\end{array}$ & $\begin{array}{l}\text { extremamente } \\
\text { necessária } \\
\text { para } \\
\text { viabilidade e } \\
\text { sucesso do } \\
\text { empreendime } \\
\text { nto }\end{array}$ \\
\hline
\end{tabular}

Quadro 2 - Síntese de respostas dos instrumentos de pesquisa

O Hotel localizado em Caxias do Sul é a organização, das quatro pesquisadas, que apresenta a maior formalização nos processos, característica de hospedagem para o público executivo, em que os serviços e a estrutura são, na sua maioria, padronizados. A aplicação de ferramentas modernas de gestão faz com que a empresa se destaque na gestão estratégica hoteleira.

Os serviços prestados, assim como a visão gerencial inovadora da proprietária e a estrutura da Pousada localizada em Gramado são de alto padrão. Os gestores utilizam várias ferramentas, como cinco forças de Porter, matrizes BCG e SWOT, além de análise de tendências do mercado local. A gestão é, entretanto, informal em vários aspectos, como na definição do negócio, missão, visão, princípios, valores, objetivos e estratégias. 
A gestão da Pousada localizada em São Francisco de Paula é informal e pouco profissionalizada. Mas isso não significa que a Pousada não ofereça serviços de qualidade e que não seja lucrativa. Pelo contrário, os resultados são satisfatórios. Os gestores não utilizam ferramentas de gestão estratégica e de avaliação de desempenho. A tomada de decisão é baseada em demandas de curto prazo.

A gestão da Pousada localizada em Bento Gonçalves é profissionalizada, utilizando adequadamente ferramentas de gestão. A formação da equipe é seu fator característico. Com a atuação da família em outros negócios, aplica-se a cultura da gestão estratégica nas práticas de gestão hoteleira.

\section{Considerações Finais}

Os gestores de organizações hoteleiras familiares da Serra Gaúcha, em especial, as pesquisadas neste trabalho, contribuem para o desenvolvimento turístico da região por meio do empreendedorismo e da capacidade de atendimento a segmentos de público exigentes. As organizações pesquisadas apresentam aspectos, como os preços das diárias e atendimento de clientes de alto padrão aquisitivo, o que as diferenciam em relação aos concorrentes, além de apresentarem resultados satisfatórios em taxas médias anuais de ocupação.

O objetivo geral deste estudo foi analisar a utilização de ferramentas para formular, implantar e monitorar estratégias de gestão organizacional pelos gestores de empresas hoteleiras familiares da Serra Gaúcha. Para os proprietários e gestores das organizações analisadas, o desempenho e os resultados são de acordo com suas expectativas. Eles concordam, porém, que a utilização de ferramentas de avaliação de desempenho às tornariam mais eficientes em seus processos, minimizando riscos de problemas futuros. A justificativa para a não utilização das ferramentas de gestão e de avaliação de desempenho por aqueles que não as utilizam está relacionada a dois fatores: conformidade com os resultados positivos e falta de profissionais qualificados para implantá-las.

As organizações hoteleiras pesquisadas dispõem de estrutura adequada, mas seus gestores salientam a importância de ampliar e de melhorar as ferramentas de gestão de suas organizações a fim de maximizar os resultados. Apropriar-se de tais ferramentas não seria prioridade para os gestores, ou eles não acreditam ter o perfil de gestor estrategista. A pesquisa mostrou que, mesmo em aspectos comuns, o hotel e as pousadas analisados diferem 
entre si quanto à utilização de ferramentas de gestão estratégica, assim como na compreensão do significado de estratégia.

Quanto ao objetivo específico de verificar se os gestores definem as diretrizes organizacionais e monitoram as variáveis microambientais e macroambientais, observa-se a dificuldade de as organizações utilizarem ferramentas. A disciplina e profissionais habilitados a utilizá-las facilitariam o processo de tomada de decisão e de inovação, fatores importantes para um segmento de mercado exigente e em busca de novidades.

Ainda que as análises sejam realizadas de maneira informal, os empreendedores são pessoas informadas e esclarecidas. Os conceitos e as abordagens teóricas de avaliação de desempenho das práticas de gestão hoteleira nas organizações familiares estudadas mostram que as ferramentas estratégicas são importantes para maior lucratividade e para maior reconhecimento no mercado competitivo do turismo.

Em relação ao objetivo específico de identificar as principais dificuldades e as visões dos gestores sobre a importância de ferramentas de mensuração e de avaliação de desempenho, o principal elemento destacado pelos proprietários é a carência de profissionais qualificados a fim de utilizar as ferramentas de gestão de forma adequada, contribuindo para a maximização dos resultados. O próprio desconhecimento dos proprietários faz com que tais ferramentas não sejam aplicadas.

As ferramentas de gestão estratégica contribuem, efetivamente, para a vantagem competitiva das empresas hoteleiras familiares. Sua maior aplicação pelos gestores proporcionaria mais otimização dos resultados e mais vantagens competitivas às empresas hoteleiras familiares analisadas.

Este estudo enfatizou conceitos e ferramentas estratégias, mostrando oportunidade para continuar as reflexões e a produção de conhecimentos aplicáveis e necessários e na gestão das organizações hoteleiras familiares. Justifica-se a continuidade da produção e da publicação de pesquisas na área também em razão de que entre 551 artigos publicados em seis dos principais periódicos brasileiros de turismo, no período de abril de 2008 a abril de 2012, é limitado o número de estudos sobre gestão estratégica de empresas hoteleiras familiares.

\section{Referências}

ABIH - Associação Brasileira da Indústria de Hoteis. Disponível em: <http;//www.abih.org.br>. Acesso em: 21 de nov. 2011. 
ANSOFF, H. Igor, McDONNELL, Edward J. Implantando a administração estratégica. São Paulo: Atlas, 2009.

ASSEN, Marcel van; BERG, Gerben van den; PIETERSMA, Paul. Modelos de gestão: os 60 modelos que todo gestor deve conhecer. São Paulo. Pearson Prentice Hall, 2010.

BARDIN, L. Análise de conteúdo. Lisboa: Edições 70, 1977.

BARROS, A.J.P.; LEHFELD,N.A.S. Projeto de pesquisa: propostas metodológicas. Petrópolis: Vozes, 1991.

BENI, Mário Carlos. Globalização do turismo: megatendências do setor e a realidade brasileira. São Paulo: Aleph, 2003.

BRUNELLI, Mariana; MACEDO-SOARES, Diana. Oportunidades e ameaças na indústria do turismo: análise estratégica relacional do caso dos hotéis líderes da cidade do Rio de Janeiro, Brasil. Revista Turismo em Análise Vol. 23, N. 1. São Paulo, 2012.

CÂMARA DE INDÚSTRIA, COMÉRCIO E SERVIÇOS DE CAXIAS DO SUL (CIC). Disponível em: <www.cic-caxias.com.br> Acesso em 10 de dez. 2011.

CASTELLI, Geraldo. Administração Hoteleira. Caxias do Sul: EDUCS, 2003.

CERTO, Samuel C.; PETER, J. Paul; MARCONDES, Reynaldo Cavalheiro; CESAR, Ana Maria Roux. Administração estratégica: planejamento e implantação da estratégia. São Paulo: Pearson Education do Brasil, 2005.

ENSSLIN, Leonardo; DUTRA, Ademar. Ferramentas de avaliação de desempenho organizacional. In: ANGELONI, Maria Terezinha; MUSSI, Clarissa Carneiro (org). Estratégias: formulação, implementação e avaliação: o desafio das organizações contemporâneas. São Paulo: Saraiva, 2008.

FERNANDES, Bruno Henrique Rocha, BERTON, Luiz Hamilton. Administração estratégica. São Paulo: Saraiva, 2005.

FOSTER, D. L. Introducción a los viajes e al turismo. México: Mc Grow Hill, 1999.

GIMENEZ, Sara; GIMENEZ, Fernando. Atitude empreendedora e estratégia em pequenos e médios hotéis. Revista Turismo, Visão e Ação. Vol. 12, N. 1. Itajaí (SC), 2010.

GOHR, Cláudia; SANTOS Luciano. Estratégias competitivas para empresas turísticas: um estudo no setor hoteleiro de um município do litoral catarinense. Revista Turismo em Análise Vol. 21, N 2. São Paulo, 2010.

HERRERO, Emilio. Balanced scorecard e a gestão estratégica: uma abordagem prática. Rio de Janeiro: Elsevier, 2005.

IBGE - Instituto Brasileiro de Geografia e Estatística. Disponível em: <www.ibge.gov.br>. Acesso em: 10 de jun. 2012.

JESUS, Marcos; MACHADO, Hilka; JESUS, Anderson. Sucessão familiar: um estudo de caso no setor de turismo. Revista Turismo, Visão e Ação V 11. N 2. Itajaí (SC), 2009.

KAPLAN, Robert S.; NORTON, David P.; A estratégia em ação: balanced scorecard. Rio de Janeiro: Elsevier, 1997.

.Organização orientada para a estratégia: como as empresas que adotam o balanced scorecard prosperam no novo ambiente de negócios. Rio de Janeiro: Campus, 2000.

.Kaplan e Norton na prática. Rio de Janeiro: Elsevier, 2004. 
Elsevier, 2004.

Mapas estratégicos: convertendo ativos intangíveis em resultados tangíveis. Rio de Janeiro: . Alinhamento: usando o balanced scorecard para criar sinergias corporativas. Rio de Janeiro: Elsevier, 2006.

A execução Premium: a obtenção de vantagem competitiva através do vínculo da estratégia com as operações do negócio. Rio de Janeiro: Elsevier, 2008.

KLUYVER, Cornelis A. de; PEARCE II, John A.; Estratégia: uma visão executiva. São Paulo: Pearson Prentice Hall, 2007.

LODI, João Bosco. A empresa familiar. São Paulo: Pioneira, 1998.

LOHMANN, Guilherme, e PANOSSO NETTO, Alexandre. Teoria do Turismo: conceitos, modelos e sistemas. São Paulo: Aleph, 2008.

LOVELOCK, Christopher. WRIGHT, Lauren. Serviços: marketing e gestão. São Paulo: Saraiva, 2001.

MARTINS, Ricard; LOBO, Débora; LABEGALINI, Letícia; CARRIERI, Alexandre. Atributos estratégicos nas compras de estabelecimentos de hospedagens: estudo das pousadas de Ouro Preto e Tiradentes no roteiro turístico "Estrada Real". Revista Turismo em Análise Vol. 21, N 2. São Paulo, 2010.

MINISTÉRIO DO TURISMO DO BRASIL. Disponível em: <www.turismo.gov.br> Acesso em 10 de junho de 2012.

MINTZBERG, Henry. AHLSTRAND, Bruce. LAMPEL, Joseph. Safári de estratégia: um roteiro pela selva do planejamento estratégico. Porto Alegre: Bookman, 2000.

MORAES, Roque. Análise de Conteúdo: limites e possibilidades. In: ENGERS, M.E.A. (Org). Paradigmas e metodologias de pesquisa em educação. Porto Alegre: EDIPUCRS, 1994.

OLIVEIRA, Djalma de Pinho Rebouças de, Planejamento estratégico: conceitos, metodologia e práticas. São Paulo: Atlas, 2009.

Empresa Familiar: como fortalecer o empreendimento e otimizar o processo decisório. São Paulo: Atlas: 1999.

PARASURAMAN, A.; ZEITHAML, V.; BERY L. A conceptual model of service quality and its implications for future research. Journal of Marketing. V. 49, p. 41 - 50, 1985.

PEDROSA, Maria Angélica; SOUZA, Eda de. Atitude empreendedora no setor hoteleiro brasileiro: um estudo em pequenos e grandes hotéis no Distrito Federal. Revista Turismo, Visão e Ação. Vol. 11, N. 3. Itajaí (SC), 2009.

PEREIRA, Yákara V.; LUCENA, Eduardo. Estratégias Adotadas pela Accor Hotels do Brasil entre 1974 e 2006. Revista Turismo em Análise, Vol. 20, N. 1. São Paulo, 2009.

PORTER, Michael E.; Estratégia competitiva: técnicas para análise de indústrias e da concorrência. Rio de Janeiro: Elsevier, 2004.

PRAHALAD, C. K.; HAMEL, Gary; Competindo pelo futuro: estratégias inovadoras para obter o controle do seu setor e criar os mercados de amanhã. Rio de Janeiro: Elsevier, 2005.

PREFEITURA MUNICIPAL DE BENTO GONÇALVES. Disponível em: <http://www.bentogoncalves.rs.gov.br> Acesso em: 15 de nov. 2011.

PREFEITURA MUNICIPAL DE CAXIAS DO SUL. Disponível em: <http://www.caxias.rs.gov.br> Acesso em: 15 de novembro de 2011. 
PREFEITURA MUNICIPAL DE GRAMADO. Disponível em: <http://www.gramado.rs.gov.br> Acesso em: 12 de dezembro de 2011.

PREFEITURA MUNICIPAL DE SÃO FRANCISCO DE PAULA. Disponível em: <http://www.saofranciscodepaula.rs.gov.br> Acesso em: 15 de novembro de 2011.

RIBEIRO, Helena Charko. A hotelaria na cidade de Porto Alegre: gestão de redes e gestão familiar. Dissertação de Mestrado em Turismo. PPGTur, Caxias do Sul: UCS. 2005.

SCHUCH, Carlos Honorato. Desempenho da cadeia produtiva na indústria do turismo. In: BARRETTO, Margarida; REJOWSKI, Mirian (org.). Turismo: interfaces, desafios e incertezas. Caxias do Sul: Educs, 2001.

SFODERA, Fabiola. The spread of yield management practices. Nova York: Springer Velag, 2011.

SINDICATO DA HOTELARIA, BARES, RESTAURANTES E SIMILARES DA REGIÃO DAS HORTÊNSIAS (SHRBS-RH). Disponível em: <http://www.serragauchaturismo.com.br > Acesso em: 12 de dezembro de 2011.

SINDICATO DE HOTÉIS, RESTAURANTES, BARES E SIMILARES DA REGIÃO UVA E VINHO. Disponível em: <www.sidireregiao.com.br> Acesso em: 12 de dezembro de 2011.

TEIXEIRA, Omar; ROSSETTO, Carlos; CARVALHO, Carlos. A relação entre o ambiente organizacional e o comportamento estratégico no setor hoteleiro de Florianópolis - SC. Revista Turismo Visão e Ação Vol. 11, N 2. Itajaí (SC), 2009.

TOMAZZONI, Edegar L. Turismo e desenvolvimento regional: dimensões, elementos e indicadores. Caxias do Sul (RS): EDUCS, 2009.

VASCONCELlOS FILHO, Paulo de, PAGNONCELLI, Dernizo. Construindo estratégias para competir no Século XXI. Rio de Janeiro: Elsevier, 2001.

WALKER, John R. Introdução à hospitalidade. Barueri: Manole, 2002.

WRIGHT, Peter L., KROLL, Mark J., PARNELL, John. Administração estratégica: conceitos. São Paulo: Atlas, 2009.

Recebido em: 04/01/2012 ( $1^{\mathrm{a}}$ versão $)$ - 09/07/2012 ( $2^{\mathrm{a}}$ versão)

Aprovado em: 28/11/2012 